\title{
Um Jesus histórico é possível? Abordagens e aspectos teórico-metodológicos de pesquisa
}

\author{
An historical Jesus is possible? Approaches and theoretical \\ methodological aspects of research
}

CHEVITARESE, André Leonardo; FUNARI, Pedro Paulo A. Jesus histórico: uma brevíssima introdução. Rio de Janeiro: Klínē, 2012. 76p.

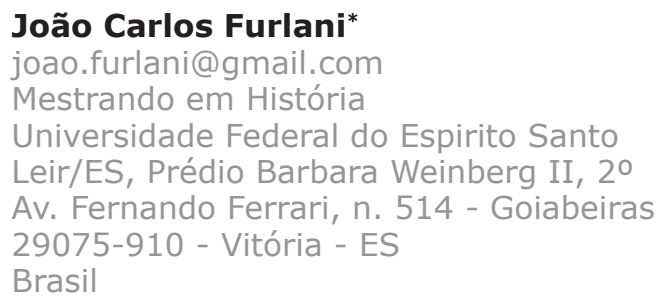

Palavras-chave

Cristianismo; Objeto histórico; Historiografia.

Keywords

Christianity; Historical object; Historiography. 
Personagens históricas que possuem repercussão por séculos ou milênios e que persistem como poderosos lugares de memória não são tão comuns assim, mas elas existem. Esse é o caso de Jesus de Nazaré que, mesmo não tendo deixado nada escrito, assim como o filósofo grego Sócrates ou Sidarta Gautama, também conhecido como Buda, é conhecido e reverenciado até os dias atuais.

Falar sobre a pessoa de Jesus não é o mesmo que falar sobre fé e religião. É claro que uma coisa pode envolver a outra, mas ambas podem ser enxergadas de maneiras distintas. E é isso que podemos ver no livro Jesus histórico: uma brevíssima introdução, escrito por André Leonardo Chevitarese e Pedro Paulo A. Funari, no qual um dos objetivos é mostrar, de maneira breve e introdutória, como Jesus de Nazaré, o homem que viveu há mais de dois mil anos, pode ser estudado como uma personagem histórica. A intenção dos autores, nessa obra, não é abranger todos os pontos concernentes a Jesus; nem o cristianismo em si, exceto nos momentos em que o mesmo influi para a pesquisa do Jesus histórico. A intenção é, numa perspectiva historiográfica, expor o que se sabe sobre Jesus e as discussões propostas por estudiosos acerca de sua vida.

Falar sobre um Jesus histórico não é algo simples. Ao contrário, é mais complexo do que aparenta, o que, consequentemente, pode levar a considerações distintas e conflitantes. Todavia, ao analisar Jesus como objeto histórico, considerações sobre a própria história são essencialmente importantes. Considerando que a história se faz com documentos, que o passado já não mais existe e apenas podemos conjecturar a seu respeito por meio de testemunhos, diretos ou indiretos, materiais ou imateriais, já temos uma noção inicial de como o Jesus histórico é visualizado atualmente. Nesse sentido, podemos ponderar sobre quais seriam as fontes para a pesquisa sobre Jesus. Os autores respondem a essa questão mencionando os manuscritos do Novo Testamento; as escavações arqueológicas; os achados de Qumran; as descobertas de Nag Hammadi; os escritos judaicos; além dos testemunhos externos ao ambiente judaico-cristão do primeiro século d.C.

Sem dúvida, os evangelhos são os documentos mais conhecidos, por constituírem relatos sobre vida e morte de Jesus. De acordo os autores, ao refletirmos sobre o próprio vocábulo "evangelho", que pode ser traduzido como "boa notícia", logo veremos que seu conteúdo se refere à vinda de Jesus como salvador da humanidade. ${ }^{1}$ Segundo esse mesmo ponto de vista, Linda Woodhead (2004, p. 16), em concordância com diversos outros autores, observa que as narrativas dos evangelhos podem ser explicadas como tentativas de adequação da vida de Jesus à lógica da expectativa judaica. Além de que, não se pode esquecer, esses textos foram escritos em grego e em períodos distintos após a morte de Jesus.

\footnotetext{
${ }_{1}^{1}$ Da raiz grega eúayẏ̇̀ıv (euangelion), os evangelhos são considerados como uma espécie de gênero literário, marcado por seu conteúdo que retrataria as "boas novas". Os quatro evangelhos considerados como canônicos (Mateus, Marcos, Lucas e João) não são meros relatos narrativos, mas também são literaturas de divulgação, que promovem discursos, parábolas, testemunhos e relatos de Jesus em vida, bem como pós-ressurreição.
} 
No que se refere às cartas ou epístolas, temos de levar em conta que estas constituem um gênero literário próprio, muito utilizado pelos primeiros cristãos. Como afirma Bakhtin (1992), a carta, em suas diversas formas, faz parte dos gêneros discursivos, sejam eles particulares ou públicos, oficiais ou não, nos revelando informações tanto acerca do destinatário quanto do remetente. As cartas ou epístolas, na Antiguidade, podiam ser enviadas a fim de auxiliar o correspondente, aconselhá-lo, exortá-lo, admoestá-lo ou consolá-lo (MARTINS 2011, p. 67), segundo determinados preceitos, assim como vemos no caso dos paleocristãos.

Já as fontes arqueológicas remetem, em sua maioria, a situações da vida cotidiana. Acerca de nosso assunto, diversas descobertas têm confirmado passagens dos evangelhos, como, por exemplo, a prática de crucificação, na qual o condenado era pregado numa estaca de madeira, diferentemente da tradição conhecida em que, na maior parte das vezes, era feito uso de cordas para amarrar os indivíduos. Todavia, outras fontes, escritas ou de cultura material, desafiam "a concepção de que nos estágios mais antigos da Igreja era unânime a fé na ressureição de Jesus" (CHEVITARESE; FUNARI 2012, p. 18). Para Chevitarese e Funari, seguindo outros especialistas, nem mesmo os evangelhos considerados canônicos (ou seja, os de Mateus, Marcos, Lucas e João) concordam em determinados assuntos, como, por exemplo, ao se referirem às tradições sobre a concepção de Jesus por intermédio do Espírito Santo, narrativa ausente, por exemplo, em Marcos.

Pontos interessantes são ressaltados ao longo de todo o livro Jesus histórico: uma brevíssima introdução, como o fato de Jesus só receber o nome "Cristo", que significa "ungido" de Deus, após sua morte. Isso significa, em outras palavras, que Jesus não era chamado de Cristo em vida, mas apenas depois de sua morte passou a ser conhecido como "Jesus Cristo, Filho de Deus" (Mc. 1, 1).

Os autores, de forma breve, trazem informações concernentes ao debate sobre a vida de Jesus. Quanto a isso, um elemento importante que não deve ser desconsiderado é a relação da personagem com João Batista. Jesus, como pregador, teria sido muito diferente de João, pois não se vestiu como o profeta Elias (Mc 1, 6). Ao sair do Rio Jordão para pregar ao povo em suas aldeias, não se apresentou como um homem consagrado a Deus, que deveria abster-se de vinho e fermentados - ao contrário, bebeu e comeu carne. Em suma, após uma fase inicial de convivência com João Batista, Jesus teria se tornado um pregador errante, sendo conhecido por seus ensinamentos simples, diretos e cortantes, discursos que emanavam autoridade na relação com os menos favorecidos, e também por suas parábolas, algumas de intepretação complexa. ${ }^{2}$

Nas investigações sobre o Jesus histórico, em algum momento, nos depararemos com a questão das ações miraculosas. Contudo, sabemos que

\footnotetext{
2 Proveniente do termo grego параßо入n் (parabolē) , as parábolas podem ser consideradas como um tipo de analogia. Uma parábola é uma sucinta história didática, em prosa ou verso, que ilustra uma ou mais lições ou princípios, em grande parte, de maneira simples. Numa parabóla, muitas vezes, encontramos um dilema moral a ser solucionado, para, então, termos respostas práticas para a vida (GOWLER 2000, p. 99).
} 
os milagres faziam parte do cotidiano do homem antigo ou, ao menos, eram percebidos como algo plenamente possível, a depender de diversos fatores, ressaltam os autores. Além disso, é seguro que os feitos prodigiosos possuíam forte apelo popular. Todavia, os saduceus, fariseus ou essênios, judeus considerados instruídos e cultos, não se deixavam seduzir por manifestações prodigiosas, nem mesmo as apreciavam (CHEVITARESE; FUNARI 2012, p. 32).

Não se restringindo às questões específicas sobre Jesus, os autores traçam, em sua obra, também uma breve trajetória das concepções, métodos e mudanças que ocorreram no limiar da pesquisa historiográfica sobre o Jesus histórico desde o período anterior ao Iluminismo, no século XVIII.

De forma geral, antes do Iluminismo, Jesus não era estudado como uma figura histórica no sentido moderno. Logo, os não-cristãos pouco interesse dispensavam a sua figura. Nesse momento, os próprios cristãos encaravam as narrativas bíblicas como lembranças estritamente históricas da vida do Nazareno.

Muitos estudiosos, ao analisar os evangelhos, ou tentar ordená-las cronologicamente, esbarram em algumas questões geradoras de conflitos e discordâncias. Dependendo da forma e da intenção com a qual a investigação está sendo conduzida, certos argumentos são correntes, como já expressava Albert Schweitzer. Para o autor, Martinho Lutero declarou que os evangelhos não seguiam nenhuma ordem específica sobre as lembranças dos atos e milagres de Jesus, o que não seria algo relevante. Além disso, Lutero prossegue: "se uma dificuldade se levanta em relação à Sagrada Escritura e nós não podemos resolvê-la nós devemos deixá-la de lado" (SCHWEITZER 2003, p. 13). Essa visão é corrente entre os interessados no Jesus da fé, em contraste com um Jesus histórico.

Já num contexto influenciado pelo Iluminismo, no qual questionamentos filosóficos impactaram diretamente os campos da política e da religião, Chevitarese e Funari (2012, p. 40-41) declaram que houve uma "primeira busca pelo Jesus histórico", marcada, principalmente, pelas biografias dessa personagem, que variavam em seus conteúdos, métodos e hipóteses - como a afirmação segundo a qual as curas de Jesus teriam ocorrido por meio de técnicas terapêuticas, ou mesmo que tudo sobre Jesus não passava de mito. Já na primeira metade do século $X X$, um grande ceticismo vigorou sobre a possibilidade de se analisar a figura de Jesus por um viés histórico. Alguns especialistas, como Albert Schweitzer, chegaram até mesmo a declarar que seria melhor deixar a questão do Jesus histórico de lado. O que, para alguns cristãos, foi um alívio, uma vez que bastava que Jesus tivesse nascido de uma virgem, vivido sem pecado, morrido para remir os pecados da humanidade e ressuscitado três dias depois (CHEVITARESE; FUNARI 2012, p. 49).

A segunda metade do século XX foi marcada pela experiência do pós-guerra, na qual até mesmo a figura de Jesus foi utilizada como aparato para o nazismo, uma vez que, entre 1933 e 1945, fortaleceu-se a ideia de que Jesus não era judeu, mas que esses últimos foram os grandes responsáveis por sua crucificação. Essa perspectiva influenciou de diversas maneiras as interpretações sobre Jesus. Como consequência, especialistas alemães se 
insurgiram contra essa visão, o que reavivou as pesquisas sobre o Jesus histórico, agora marcadas pela contribuição da Arqueologia, Antropologia, Filosofia e História, que passam a contribuir fortemente para o avanço das pesquisas (CHEVITARESE 2013a, p. 7).

Já em 1985, temos outro evento importante para as pesquisas sobre o Nazareno, o chamado The Jesus Seminar, fundado por Robert Funk. Esse seminário teve o propósito de buscar analisar Jesus sob um ponto de vista histórico, e possuiu três fases, que os autores, de forma sucinta, buscaram apresentar. Em suma, pretendeu-se isolar qual teria sido o núcleo básico dos ditos e feitos de Jesus, diferenciando-os das interpolações posteriores. Todavia, devido ao caráter objetivo e reconstrutor do seminário, há autores que o consideram como uma tentativa de busca, no fim das contas, por um "Jesus real", o que, teoricamente, diferencia-se de uma análise histórica mais subjetiva, mas sendo, em certa medida, próximo a ele (SCHIAVO 2009, p. 30). ${ }^{3}$

Um ponto essencial a se destacar é o questionamento sobre como as pessoas se relacionavam com a memória na Antiguidade, reflexão necessária para as pesquisas sobre o Jesus histórico e o paleocristianismo. Segundo Cheviaterese e Funari (2012, p. 12), a alfabetização não era difundida e a maioria das pessoas era analfabeta. Mesmo as que dominavam a escrita, se fiavam na memória para se lembrar do que liam. Os livros já existiam, mas eram rolos que eram abertos para que pudessem ser lidos. Os livros ou volumina, nesse momento, eram transcritos, coluna a coluna, em longos retângulos de papiro ou de pergaminho, enrolados em cilindro, que se iam desenrolando à medida da necessidade da leitura, para em seguida se enrolar de novo, procedimento distinto daquele da Antiguidade Tardia, quando o volumen cede lugar ao codex, formado de cadernos cosidos que permitam edições de tamanhos consideráveis (MARROU 1977, p. 13-14). No caso do volumen, era, portanto, impraticável realizar uma rápida consulta a passagens de obras como hoje fazemos com documentos impressos e digitais. Ou seja, na Antiguidade, as pessoas decoravam o que tinham lido ou ouvido, o que Ihes proporcionava reproduzir longos trechos. Além disso, a memória, segundo os autores, é subjetiva e estamos sempre sujeitos a recordar determinados momentos da vida, manter certas frases e situações e a esquecer e suprimir outras. E foi por meio desses e de outros mecanismos que os seguidores do Nazareno recordaram ou suprimiram certos episódios e ditos de Jesus (CHEVITARESE; FUNARI 2012, p. 13).

Convém ressaltar que essa "busca por um Jesus histórico" não se pauta pela simples objetividade, na qual há a procura por uma "verdade" sobre Jesus ou um "Jesus real", como alguns pesquisadores insistem em afirmar - mesmo que alguns ainda o façam. Ao se trabalhar com aspectos da memória, de narrativas orais e de discursos, a subjetividade, as representações e o caráter religioso também devem ser levados em conta mediante uma análise que tende cada vez mais a ser transdisciplinar.

\footnotetext{
${ }^{3}$ Os resultados dos debates, além dos métodos e consequências para o estudo do Jesus histórico, provenientes do Seminário de Jesus foram publicados, incorporados e também críticas em diversas obras. Todavia, podemos encontrar uma explanação sobre os mesmos em Schiavo (2009).
} 
Pautando-se nas transformações epistemológicas ocorridas na historiografia, bem como nas contribuições que o Seminário de Jesus puderam proporcionar, as investigações atuais sobre o Jesus histórico ampliarem consideravelmente seus fundamentos teórico-metodológicos, incorporando perspectivas advindas da Sociologia, Antropologia, História, Arqueologia, Ciências da Religião, Linguística, entre outros campos de estudo. Para os autores, pesquisar o Jesus histórico não significa iluminá-lo sob um ponto de vista exclusivo da História, em virtude da intensa transdisciplinaridade que envolve tal temática acerca de uma das personagens mais conhecidas em todos os tempos. Desse modo, há sempre a possibilidade de visualizarmos um Jesus tanto histórico, como sociológico, religioso ou narrativo, construído de diversas maneiras e em momentos distintos, como assinala Chevitarese (2013a, p. 9), no caso da produção cinematográfica sobre Jesus, na qual os filmes nos revelam as recepções que a época contemporânea faz acerca de Jesus e de seu tempo. Mais precisamente, isso quer dizer que as construções fílmicas revelam mais informações sobre as interpretações que a contemporaneidade faz dessa figura histórica do que sobre o contexto do século I propriamente dito. ${ }^{4}$

Por fim, podemos dizer que Jesus histórico: uma brevíssima introdução, mesmo que de forma sucinta, cumpre com seu propósito: o de servir de leitura preliminar e indispensável para um tema cada vez mais popular, que é o Jesus histórico. Seu caráter introdutório não significa que a obra deva ser tida como superficial, uma vez que, nela, encontramos referências importantes quanto a perspectivas de análise atuais e à historiografia recente, o que lhe permite atuar como bibliografia de apoio, além de instigar o leitor a se debruçar cada vez mais sobre um tema tão rico e complexo.

\section{Referências bibliográficas}

BAKHTIN, Michail. Estética da criação verbal. São Paulo: Martins Fontes, 1992.

BÍBLIA DE JeRUSALÉM. São Paulo: Paulus, 2002.

CHEVITARESE, André Leonardo. Entrevista com André Leonardo Chevitarese: um novo olhar sobre o estudo do Jesus histórico e do paleocristianismo. Romanitas - Revista de Estudos Grecolatinos, n. 1, p. 5-12, 2013a. . Jesus no cinema: um balanço histórico e cinematográfico entre 1905 e 1927. Rio de Janeiro: Klínē, 2013b. v. 1.

; FUNARI, Pedro Paulo A. Jesus histórico: uma brevíssima introdução. Rio de Janeiro: Klínē, 2012.

GOWLER, David B. What are they saying about the parables? New York; Mahwah: Paulist Press, 2000.

\footnotetext{
${ }^{4}$ Para mais informações sobre a representação de Jesus no cinema, sob um viés histórico cf.: Chevitarese 2013b.
} 
MARROU, Hénri-Irinée. Décadence romaine ou antiquité tardive? IIIO-IVo siècle. Paris: Éditions du Seuil, 1977.

MARTINS, V. G. D. Reflexão sobre a escrita epistolar como fonte histórica a partir da contribuição da teoria da literatura. Língua e literatura, v. 13, n. 20, p. 61-72, 2011.

SCHIAVO, Luigi. A busca pelas palavras e atos de Jesus: o Jesus Seminar. Caminhos, v. 7, n. 1, p. 29-53, 2009.

SCHWEITZER, Albert. A busca do Jesus histórico. São Paulo: Novo Século, 2003.

WOODHEAD, Linda. Christianity: a very short introduction. Oxford: Oxford University Press, 2004. 